\title{
Memoria política desde los otros: Guerra Civil de 1948 en Costa Rica. Una perspectiva desde el paradigma de la complejidad de la prensa latinoamericana
}

\author{
Political memory from the others: 1948 Civil \\ War in Costa Rica. An outlook from the \\ paradigm of Latin American press complexity
}

Macarena Barahona Riera

Escuela de Estudios Generales

Universidad de Costa Rica intitucionallilliana.barahona@ucr.ac.cr

Carolina Mora Chinchilla

Escuela de Estudios Generales

Universidad de Costa Rica carolina.mora@ucr.ac.cr

\section{Resumen}

Las autoras hacen un estudio de cómo la prensa escrita latinoamericana (México, Guatemala, Panamá, Colombia y Chile) aborda el tema de la Guerra Civil de 1948 en Costa Rica, así como el interés de los Estados Unidos de América en el conflicto.

Palabras claves: Guerra Civil en Costa Rica, trasiego de armas, prensa latinoamericana. 


\begin{abstract}
The authors analyze hour Latin American press (Mexico, Guatemala, Panamá, Colombia, and Chile) approaches the subject of 1948 Civil War in Costa Rica, as well as the interest of the United States of America in this political conflict.
\end{abstract}

Keywords: Civil War in Costa Rica, arms transfer, Latin American press.

\section{Introducción}

$\mathbf{E}$ n el humanismo contemporáneo, la interdisciplinariedad y la transdisciplinariedad son parte fundamental del quehacer científico. Nuestros retos de ampliar las particularidades de los contextos en temas concretos como en temas con contextualizaciones internacionales, nos enfrentan a los paradigmas humanistas que se basan en los pensamientos de la denominada teoría de la complejidad. Las conexiones en temas históricos como la Guerra Civil de 1948 serían construcciones de un pensamiento complejo en la infinitud de la inmensidad de lo más sencillo a lo más complejo.

Tenemos la oportunidad de ampliar nuestras perspectivas de la Guerra Civil de 1948 con el aporte de las nuevas tecnologías y el desarrollo de instituciones culturales y educativas de América Latina. El contexto a través de la prensa internacional nos aporta nuevas particularidades tanto de actores como perspectivas, planteamientos políticos, unos panoramas internacionales desde distintos puntos de vista acerca de una guerra y su concatenación hacia nuevos sucesos políticos con otras naciones de Latinoamérica y de impacto regional.

Dentro del pensamiento complejo, el filósofo francés Edgar Morin nos plantea: “el todo posee cualidades o propiedades que no se encuentran en las partes si estas se separasen unas de otras y determinadas cualidades o propiedades de las partes pueden resultar inhibidas por las restricciones surgidas del todo. Efectivamente, hay que reconocer el todo para conocer las partes" (Morin, 2001, p. 38).

El objetivo de nuestro trabajo en el nivel metodológico es analizar la narrativa particular de la nota de prensa con respecto al conocimiento general de la historiografía costarricense de la Guerra Civil, en el camino de la memoria política. Se busca unir las partes que han sido preservadas en los distintos medios escritos que más abajo se especifican, porque es nuestro interés visibilizar la geopolítica y Costa Rica, como un objetivo estratégico para el gobierno de los Estados Unidos.

Dentro del conocimiento en que se enfrenta la teoría de la complejidad buscamos las uniones de estas partes, que más adelante se establecen y se detallan. Señala Morin que:

"Complexus en latín significa lo que está tejido junto, en efecto, hay complejidad cuando son inseparables los distintos elementos que constituyen un todo (económico, político, sociológico, psicológico, afectivo o mitológico) y 
existe un tejido interdependiente, interactivo e interretroactivo entre el objeto de conocimiento y su contexto, las partes y el todo, el todo y las partes o las partes entre sí” (Morin, 2001, p.47).

Dentro del paradigma de la complejidad "se establece también la relación directa entre el caos y el orden, que han tenido una revaloración, ya que se les considera dentro de determinados contextos, junto con la crisis, más como expresión de información compleja que como una ausencia de orden, todo ello tanto en el campo de la ciencia como en el de la cultura" (Torres, 2013, p.69).

Siguiendo esta afirmación, lo que denominamos Guerra Civil en Costa Rica sería la crisis, expresión de una información compleja, que está en relación directa entre el caos y el orden en nuestro estudio. Esta relación, la constituiría la información de la prensa internacional latinoamericana, que establece relaciones directas dentro de esta información compleja, planteando lecturas diversas desde una perspectiva geopolítica, desde el sur del continente americano y otra perspectiva mesoamericana.

\section{Pasos investigativos}

Para la elaboración de este artículo se construyó una base de cientos de documentos periodísticos, que se recopilaron de las Bibliotecas Nacionales de México, Panamá, Colombia, Chile y Costa Rica, además de la Colección privada de El Imparcial de Guatemala.

Es importante señalar que gracias a la colaboración de las diferentes instituciones culturales que conservan estos periódicos, se ha creado un nuevo archivo digital en la Biblioteca Nacional de Costa Rica, que es posible visitar utilizando la tecnología contemporánea básica. La labor de estas bibliotecas de cuidado y preservación de los materiales y documentos y la entusiasta voluntad de las y los directores y personal de las bibliotecas, hicieron posible este logro.

La base cuenta con diversidad de perspectivas, ya que los diferentes periódicos responden a diversas tendencias políticas. Estos periódicos son:

- México:
a) Excelsior
b) El Nacional
c) El Universal

- Guatemala
a) El Imparcial

- Panamá
a) La Hora
b) La Nación
c) El Panamá América

- Colombia
a) El Tiempo

- Chile
a) El Mercurio

- Costa Rica
a) Trabajo
b) La Gaceta
c) La Tribuna
d) La Nación
e) El Diario de Costa Rica

El trabajo de investigación consta de una cogestión pedagógica e interdisciplinaria 
desde su concepción e inicio. La exposición visual, inaugurada el 9 de mayo de 2018 en la Biblioteca Nacional de Costa Rica, contó con los materiales internacionales tratados y seleccionados por nuestro equipo y ubicados de forma tal que pudieron entrar en diálogo con los textos nacionales. Este planteamiento es alternado con la elaboración de nuestro guión histórico, que provee al lector y visitante de información objetiva y puntual que dirigía de forma pedagógica y alternativa su visita.

La propuesta física de nuestra Exposición "Conmemoración del 70 aniversario de la Guerra Civil de Costa Rica de 1948. Exilio, Guerra y Memoria", fue inaugurada con la presentación de dos conferencistas invitados: la Dra. Laura Moreno Rodríguez de la Universidad Autónoma de México, quien disertó sobre "Los exiliados costarricenses en Ciudad de México" y el Dr. Vladimir de la Cruz, que se refirió a los "Antecedentes históricos de la Guerra Civil de 1948".

El 11 de mayo de 2018, se realizó un Foro de la Memoria, en el que se presentaron dos documentales: Las mujeres de 1948, de Macarena Barahona Riera y Ana Xóchil Alarcón, y El Codo del Diablo, de Antonio Jara. En este foro participaron los realizadores y se promovió la participación de los asistentes, muchos de ellos compartieron vívidamente los recuerdos de su infancia en los días de la guerra, así como comentarios y preguntas de asistentes.

La conmemoración de los 70 años de la Guerra Civil en Costa Rica fue posible porque se contó con la participación de diferentes instituciones educativas y culturales, así como el entusiasta apoyo de la Dra. Isabel Vásquez, del Centro de Estudios Mexicanos. Por su medio se pudo coordinar la participación de la Dra. Moreno de la UNAM, junto a la Universidad de Costa Rica, la Escuela de Estudios Generales y el Canal 15.

El Sistema Nacional de Bibliotecas y su más importante institución, la Biblioteca Nacional prestó sus instalaciones para esta conmemoración y mantuvo durante dos meses la exposición abierta a los visitantes. La directora de esta biblioteca, la Máster Laura Rodríguez y su acucioso personal, colaboraron en la búsqueda de la prensa nacional de la época, bibliografía del tema, que también se expuso, así como la contratación de gigantografías de las noticias del exterior más llamativas, que hicieron de la exposición una experiencia educativa muy agradable.

Lo más relevante ya se mencionó, la llegada de cientos documentos y periódicos de forma virtual al acerbo de la Biblioteca Nacional de Costa Rica. Sobre esto el Dr. Pablo Mora Pérez-Tejada, del Instituto de Investigaciones Bibliográficas y de la Hemeroteca Nacional Digital de México, en una nota dirigida a Laura Rodríguez, directora de la biblioteca, expresa lo importante del envío:

"En la colección de la Hemeroteca Nacional de México (HMDM) se recuperaron 51 registros publicados en el diario El Nacional. Las notas refieren principalmente sucesos relacionados con la Guerra Civil; se localizó una nota que trata justamente de la participación de México: "La intervención de México en Costa Rica fue a petición expresa 
del presidente Teodoro Picado" (16 de abril de 1948, p.1). En una segunda búsqueda, se obtuvo un resultado de 52 registros del diario Excelsior, entre éstos se localizaron las notas: "En la Embajada de México se firmó la paz en Costa Rica" (21 de abril de 1948, p.1) y "La revolución de Costa Rica se acerca a su culminación" [en un recuadro fechado en Washington se menciona la participación de varios embajadores incluido el de México]" (14 de abril de 1948, p.2). Por último, en una tercera búsqueda se revisó nuestra colección de microfilmes y se localizaron 54 notas sobre el tema de Costa Rica publicadas en el diario El Universal, sobre la participación de México. Se localizaron los artículos: "Se dejó de luchar hoy en Costa Rica. Mediaron algunos embajadores, inclusive el de México" (14 de abril de 1948, p.1,9); "Termina la lucha en Costa Rica con una aceptación de cláusulas" (16 de abril de 1948, p. 1,9$)$. Se verificó que toda la información localizada en los medios alternativos estuviera disponible en nuestras colecciones impresas" (Pedro Mora, Oficio IIB/053/2018) (19 de febrero de 2018). Debemos agregar a esto que de El Nacional, se enviaron 21 artículos y de El Universal, 55.

De Chile, la Biblioteca Nacional envió 20 artículos de El Mercurio, en los que se habla de asuntos varios relacionados con Costa Rica y su situación en general.

De Colombia, la Biblioteca Nacional envió 54 artículos de El Tiempo. Cabe recordar que durante los días de la guerra en Costa Rica, sucedieron en Colombia dos hechos fundamentales: la Conferencia de Bogotá, en la que se organizó la Organización de Estados Americanos y el asesinato de Baltazar Gaitán, candidato presidencial de Colombia, lo que provocó grandes disturbios y, al final, el inicio de una guerra.

De Panamá se obtuvieron 9 artículos de La Hora. La información obtenida de este país es reflejo de la gran preocupación de los Estados Unidos por la situación de Costa Rica. Se debe recordar la cercanía del país al Canal Interoceánico en manos norteamericanas.

Así mismo, la recuperación de los artículos sobre la Guerra Civil de Costa Rica en 1948 de El Imparcial de Guatemala fue conseguida por Macarena Barahona, en el Centro de Investigaciones Regionales de Mesoamérica (CIRMA), de Antigua, Guatemala.

Un tercer paso, luego de conseguir el material documental y hacer su exposición y la conmemoración del evento bélico, fue la elaboración de la experiencia, de nuestras lecturas de todo el material acuñado y organizado cronológicamente y el análisis que planteamos como parte del acercamiento al pensamiento complejo y la valoración de la memoria histórica. Las fuentes nos permitieron confrontar, dialogar y sintetizar los hechos en los principales días de la Guerra Civil costarricense.

Este trabajo tiene como principal propósito un objetivo pedagógico, en el cual, como ya lo hemos expuesto, se culminó la conmemoración de la guerra con la gran exposición y las actividades académicas y el foro de la memoria como actividades de difusión de nuevos materiales y documentos, así como de exposición de documentos y vídeos de nuestro patrimonio histórico. 
El acervo que actualmente quedó en la $\mathrm{Bi}$ blioteca Nacional de la colección de periódicos de México, Colombia, Panamá, Chile y Guatemala y la colección propia, sin lugar a dudas, enriquecen el patrimonio nacional.

\section{Conexiones de la prensa latinoamericana con respecto a Costa Rica en los días de la Guerra Civil}

En esta concatenación de hechos que observamos en retrospectiva de los sucesos políticos y de violencia militar en los días de la Guerra Civil de 1948, y, a través de todo el acopio documental de la prensa extranjera, se notan tres líneas fundamentales que en la narrativa de las noticias podemos establecer. A saber: la ubicación y situación estratégica de Costa Rica en el nivel geopolítico -limítrofe con Panamá, con el canal de Panamá, con la Escuela de las Américas y con el comando sur del ejército de los Estados Unidos de América-. En segundo lugar, el avance de las fuerzas sociales denominadas como el "comunismo costarricense" en la prensa, el cual se presenta como el enemigo del gobierno de los Estados Unidos y, tercero, la participación y la intervención de los países vecinos del área en los hechos bélicos directamente.

Todas estas conexiones surgidas del análisis de los diferentes artículos, notas y demás, seleccionados de la prensa regional, nos permiten la observación de un mundo de caos en que podemos construir un nuevo orden de estos sucesos, con las conexiones que organizamos, con la prensa latinoamericana y nuestra nueva lectura, a los setenta años de dichos acontecimientos.
A continuación, se hará un breve resumen de algunas informaciones aparecidas en los periódicos recopilados por vía digital. Sólo se verán algunos títulos en razón de la enorme cantidad de información obtenida; sin embargo, estos datos nos permitirán interconectar, en un primer acercamiento, los medios latinoamericanos con los costarricenses y entre ellos mismos.

\section{Panamá}

De acuerdo con lo planteado, geoestratégicamente no se puede obviar que la situación de guerra civil en Costa Rica preocupaba a Panamá, país que hospedó hasta el año 2000 a los Estados Unidos como administradores del Canal Interoceánico. En el diario La Hora se aprecian notas como la siguiente (La Hora publica editorial del Herald Tribune, 27 de marzo de 1948):

"Más que una revolución”, es el título del editorial: "...lo que hace notable a Costa Rica en esta Guerra Civil es la existencia de un pequeño, pero bien armado grupo de comunistas en peligrosa proximidad de la zona del canal y la tragedia de tal conflicto en un Estado que ha tenido tan excelente récord de elecciones libres y pacíficas... "las dificultades de Costa Rica constituyen algo más que una revolución. Virtualmente toda Centroamérica ha sido acusada de intervención en la lucha. Los cargos son de variadas formas y las respuestas, en general, han sido negativas oficiales de las naciones comprometidas".

El presidente Jiménez, de Panamá, expresó hoy en una entrevista que "El Gobierno panameño ha visto un gesto de agresión en la actitud asumida por Nicaragua con 
motivo de la revolución en Costa Rica. Jiménez dijo que "Considera que Nicaragua está violando numerosos pactos continentales que prohíben a un país intervenir en los asuntos internos de otras naciones".

El 13 de marzo de 1948, La Hora, al día siguiente de iniciados los combates en Costa Rica, publica: "Armamentos y militares transporta René Picado de México a Costa Rica". Desde México la noticia es que el general costarricense René Picado se dirigía a Estados Unidos a nacionalizarse y se asegura que compra armamento y contrata militares para llevar a su país. Se concluye con la inminencia de la guerra civil y el abandono de las negociaciones por parte de la Asociación de Banqueros ya mencionada en un diario mexicano. Las ciudades según el artículo, quedaron vacías y el comercio cerrado.

La Nación, de Panamá, el 13 de marzo en primera plana dice: Aparentemente el gobierno de Picado controla la situación en Costa Rica. Al día siguiente, el 14 de marzo en la primera plana de este diario, se lee "La capital tica en estado de sitio". Aparentemente no hay mucho control de la situación por parte del gobierno.

El diario Panamá América, el 13 de marzo de 1948, bajo el título "Guerra civil en Costa Rica”, en primera plana publica que los rebeldes ganan la primera batalla y que el gobierno suspendió las garantías constitucionales. El 15 de marzo, "Aviones de Picado bombardean posiciones de rebeldes en "La Lucha", es el titular de la primera plana. Aquí como comentario al margen no se puede dejar de mencionar el hecho de que la "leyenda popular" "canta" en un corrido que José Figueres nombró a su finca "La Lucha" por haberse iniciado allí la Guerra Civil, pero por lo visto ya se conocía el nombre del lugar, al menos para el diario Panamá América.

\section{Guatemala}

La República de Guatemala a partir de la información recopilada del periódico $E l$ Imparcial, privilegia los acontecimientos políticos y militares que se viven en Costa Rica, desde una posición y conocimiento excepcional. Se aprecia, por la gran cantidad de noticias, el manejo de información histórica, cultural y el manejo de personajes y líderes políticos. Periodistas que hacen entrevistas, hacen análisis, construyen caminos de cercanía entre las repúblicas de Guatemala y Costa Rica, siempre dentro del respeto y la objetividad del buen periodismo.

Con fecha 12 de marzo de 1948, publican lo siguiente. "Monseñor Sanabria, arzobispo de San José se mueve a favor de la paz", "no es posible que en un país que siempre ha gozado de ilimitada libertad y donde el derecho se ha impuesto como una virtud cívica, una minoría prive despiadadamente sobre la gran mayoría del pueblo", decía Arturo Valdés Oliva, director de ese diario.

En otro momento de ese mismo 12 de marzo, hablan de que René Picado está fuera del país y de que al final le echarán la responsabilidad a Manuel Mora V. y sus compañeros. A él lo buscan para una entrevista, que acuerdan para el día siguiente en la casa de Carmen Lyra, la cual se lleva a cabo. Lo describen ampliamente y 
critica a Rómulo Betancourt por abandonar las filas del socialismo.

El Imparcial, el 14 de febrero de 1948, publica: “¿Costa Rica está rompiendo su tradicional democracia?” Este editorial se refiere al clima de incertidumbre por los "extraños sucesos" en las elecciones presidenciales del domingo 8 de febrero en Costa Rica. Comparan los días de la "democracia perfecta" en Costa Rica, con la zozobra de este momento. El mismo diario, el 16 de febrero siguiente, hace noticia un comunicado de la Legación de Costa Rica, donde informa de denuncias de irregularidades electorales y la expulsión del encargado del Registro Electoral. Llama la atención que desde un mes antes de que estalle la Guerra Civil, Guatemala informa de la situación anómala de Costa Rica.

El Imparcial, de Guatemala, presenta las informaciones sobre Costa Rica desde un punto de vista más objetivo y coloca al partido comunista en una posición activa, como parte del caos político y violento de esos días. El diario le da espacio a otros autores y periodistas que señalan la defensa de la legislación social, la participación del Partido Vanguardia Popular y las organizaciones sociales, así como la importancia de la Iglesia Católica, como parte de una alianza que apoyaba a Calderón Guardia.

No debemos olvidar el momento político de democratización que vive Guatemala con el gobierno de Juan José Arévalo. El ambiente cultural y periodístico fortalece periódicos más independientes como $\mathrm{El}$ Imparcial, donde claramente la información abarca más hechos y más profundidad en su análisis. Se visibilizan en este diario, figuras políticas, hechos bélicos y contrabando de manera clara, a diferencia de lo visto en algunos periódicos de otras naciones latinoamericanas.

El gobierno de Guatemala, directamente involucrado con las fuerzas rebeldes bajo el compromiso de la Legión del Caribe con José Figueres en armas, hombres y aviones de la Fuerza Aérea Guatemalteca, fue noticia de los periódicos mexicanos que, como veremos luego, estaban interesados en mostrar la no participación de México en estos asuntos.

\section{México}

Como se puede observar en el artículo de la Dra. Laura Moreno de la Revista Estudios $\left(N^{\circ} 37,2018\right)$ "A 70 años de la Guerra Civil 1948, José Figueres en México", desde el año 1942 en México, se da seguimiento a las actividades políticas de José Figueres en la Ciudad de México y sus conexiones con los exiliados de El Salvador, Honduras y Guatemala. Estas conexiones son denunciadas por el mismo embajador de México en Costa Rica y por el líder político sindical Lombardo Toledano, quienes analizan y denuncian un riesgo a la soberanía de Costa Rica y un peligro para el gobierno de Calderón Guardia primero, y de Teodoro Picado, después. Se denuncia, asimismo, el envío y trasiego de armas organizados por la oposición a dichos gobiernos.

La prensa mexicana evidencia la participación de exiliados centroamericanos y del Caribe, que desde México toman parte en la Guerra Civil de Costa Rica. Militares, armas y estrategas, acuerdan desde 
tiempo atrás, participar abiertamente en el conflicto y derrocar al gobierno de Teodoro Picado.

El Excelsior, el 20 de marzo de 1948, en el artículo "Cinco países mezclados en una Rebelión", comenta la participación de Guatemala en los eventos costarricenses, con pruebas contundentes del envío de armas y municiones, lo que niega absolutamente Guatemala en la Conferencia de Bogotá, en la cual se creó la Organización de los Estados Americanos.

Laura Moreno, citada por Macarena Barahona (2015), explica que debido a las diversas intrigas entre dominicanos, costarricenses y nicaragüenses, el presidente Arévalo dio su apoyo a la causa de Figueres, aunque después de ganar la guerra, Figueres desampara a la Legión Caribe.

Ese mismo 20 de marzo en otra nota, $E l$ Excelsior decía: "La contienda de Costa Rica amenaza a Centroamérica", una de las pocas veces que el peligro ístmico se ve reflejado en este conflicto.

Ya el 17 de marzo de ese año, el mismo diario El Excelsior había publicado una nota en la que 60 revolucionarios de Costa Rica habían sido capturados por el gobierno y sobre las intenciones de Figueres.

El Excelsior, el 7 de abril de 1948, publica un extenso artículo: El Secretario de Seguridad Pública de Costa Rica se encuentra en México, en donde se hace un extenso comentario sobre la presencia del ministro René Picado, pidiendo cuentas sobre la entrega de armas a los rebeldes de Figueres y de la imposibilidad de llegar a la paz en Costa Rica si llegan a ganar los figueristas y los comunistas. René Picado estaba en México, camino a Estados Unidos, donde pediría la nacionalidad para su esposa, según la nota. Esto no deja de ser una curiosidad, en vista de la situación precaria del presidente Teodoro Picado en esos momentos.

El 6 de abril de 1948, en El Universal de México, sale una nota en primera plana bajo el título "Que volaron armas hacia Costa Rica". Explican que armas procedentes de México, ametralladoras, 400 fusiles y 35 mil cartuchos volaron en un avión de la compañía TAN, de Costa Rica.

El gobierno mexicano sabe del tráfico y contrabando de armas, según dice Laura Moreno (2018) en el artículo citado. En territorio mexicano se organizan las fuerzas rebeldes que van a invadir Costa Rica y desde ahí se compran armas e insumos militares desde 1944. En esta Guerra Civil participan los grupos antisomocistas, los del exilio dominicano, antitrujillistas y el exilio hondureño. Le brindan apoyo a José Figueres Ferrer y su grupo. Se hace evidencia una estrategia conspirativa de diferentes exiliados de varios países del área y el silencio o complicidad de algunos de estos gobiernos.

El 20 de marzo de 1948, El Nacional publicó que el Gobierno de Costa Rica denuncia que las armas de los rebeldes están siendo proporcionadas por el gobierno de Guatemala y de México y que solicita investigaciones al respecto, y así mismo, en cable internacional, esta información fue enviada al Departamento de Estado de Estados Unidos. 
El Nacional, el 9 de abril de 1948, le publica al diputado costarricense Jaime Cerdas su derecho de respuesta ante un editorial. Niega "categóricamente", tal y como él lo expresa, la entrega de armas de parte del Gobierno de México al partido Vanguardia Popular. Aclara que su partido no tiene ni ha tenido control del Estado.

En otra noticia del periódico Excelsior, del 21 de marzo de 1948, el enviado de Figueres a Nueva York, Gonzalo Facio, dio declaraciones en el sentido de la gran amenaza del comunismo, con la frase "los rojos quieren tomar Costa Rica".

Es interesante evidenciar la construcción del peligro inminente de la toma del poder por los "rojos", como la amenaza que va a existir dentro del discurso anticomunista y la construcción mental y política de los bloques hegemónicos de la división del mundo entre el capitalismo y el socialismo, presente en la Guerra Fría y que fue el espíritu de la época hasta la caída del socialismo. Los tres periódicos mexicanos enviados dan claras muestras de ese pensamiento.

El Universal, al igual que los diarios mencionados anteriormente, señala desde sus primeras páginas el tema de las armas y la compra de éstas. Sorprende que el asunto fue tema desde el 12 de marzo hasta el 21 de abril, cuando publican que asumió interinamente la presidencia de Costa Rica, Santos León Herrera.

\section{Chile}

Las relaciones con el gobierno de Chile habían sido tradicionalmente muy importantes en el nivel cultural y político desde finales del siglo XIX, cuando muchos intelectuales costarricenses habían ido a estudiar gracias a becas otorgadas por el gobierno chileno. Desde 1857 había embajada de este país en Costa Rica, lo que facilitó la relación. Lo mismo que las relaciones comerciales planteadas alrededor de 1830 .

Resalta en El Mercurio una entrevista a Julio Fuenzalida Valdivia, encargado de negocios de Costa Rica en Chile (12 de marzo de 1948). Habla de la situación de lucha que se vive en esa época. Expresa su amistad con Otilio Ulate y su preocupación por el no reconocimiento a su gane. Habla sobre los lazos de amistad que unen a Chile con Costa Rica, en especial por la formación de maestros en el Instituto Pedagógico chileno. Llama la atención, en dicha nota, la perspectiva fraterna con que plantea los difíciles momentos que vivía el país, dándole realce a las gestiones que Monseñor Sanabria acometió, como líder de la Iglesia Católica, para mediar y buscar soluciones antes de que las pérdidas humanas del enfrentamiento militar sigan en aumento.

El mismo diario de Chile, el 11 de marzo de 1948 había publicado la nota "Nuevas gestiones de tregua" en la que se comenta que el Arzobispo de San José, Víctor Manuel Sanabria, logra un acuerdo de tregua entre las facciones políticas en lucha. Las negociaciones quedan, según explican, "entre la Asociación de Banqueros".

El 20 de abril de 1948 El Mercurio publica "Tropas de Nicaragua ocuparon ayer posiciones fronterizas de Costa Rica". Esto, según dicen, se discutiría en la 
Conferencia Interamericana en Bogotá. Nicaragua alegaba que los rebeldes estaban ingresando en su territorio, por lo cual debieron defender su frontera sur. El secretario Marshall, en Bogotá, dice que hay preocupación de los Estados Unidos, lo mismo que Rómulo Betancourt.

Para el 19 de marzo de 1948, publican varias notas llamando la atención al lector sobre el tema del comunismo en el gobierno costarricense. Indican además que el gobierno pidió armas a Honduras. El Dr. Anderson junto a Isaac Zúñiga Montúfar partió a Honduras a pedir dichas armas.

El 24 de marzo de 1948 este periódico chileno decía lo siguiente: "Panamá considera que Nicaragua viola pactos continentales al interferir en Costa Rica".

La perspectiva que Chile presenta a través de las noticias y reportajes publicados en El Mercurio deja planteada una visión algo diferente de la de los otros países; lo mismo veremos con Colombia, ya que, podemos especular, no estaban involucrados directamente con ninguna de las fracciones enfrentadas en la lucha y la actitud política fue de colaborar con todo sentido con las instancias a favor de un diálogo para la paz.

Es importante señalar que el punto de referencia, en general, de la prensa chilena ubica la guerra civil de Costa Rica en la perspectiva más humana y civil, lamentando a su vez la pérdida de vidas, desde un análisis de los intereses económicos y políticos de los Estados Unidos y del movimiento anticomunista, ya muy presente en América.

\section{Colombia}

En los días de la guerra civil de Costa Rica en 1948, se dio la IX Conferencia Internacional Americana, en Bogotá. Dicha conferencia inició el 30 de marzo de 1948. Por esos mismos días se inaugura el primer congreso de estudiantes universitarios latinoamericanos, al que asistió como estudiante Fidel Castro. Iba como delegado de la Escuela de Derecho y se fundaría la Federación de Estudiantes Latinoamericanos. En 1976, El Tiempo de Colombia, mismo diario que se reseña, publicó una nota de Fidel Castro, quien siendo estudiante y delegado de la Universidad de La Habana, participaba en el congreso: "Gaitán no solamente tenía un enorme arraigo entre las masas; tenía también grandes simpatías en el propio ejército de Colombia... no es de extrañar que la oligarquía colombiana en medio de una ola de sangre, fraguara el asesinato de aquel formidable adversario al que realmente temían. El día 9 de abril salimos nosotros del hotel en espera de la entrevista que tendríamos con Gaitán, eran como las 11 de la mañana aproximadamente, cuando gentes como enloquecidas comenzaron a correr por las calles repletas de público, gritando con ojos de indescriptible asombro: ¡Mataron a Gaitán! Y así la noticia se esparció como un reguero de pólvora por toda la ciudad" (El Tiempo, 14 de noviembre de 1976, Suplemento Noticias Dominicales, grabado por Carlos Franki).

El 12 de marzo de 1948, poco antes del asesinato del líder liberal y candidato presidencial, Jorge Eliécer Gaitán, estalla la guerra civil en Costa Rica, suceso que se entremezcla en El Tiempo con las noticias de la Guerra Civil de nuestro país. 
El Tiempo resalta en sus noticias el problema de las armas con las que se está luchando en el bando figuerista, contra el gobierno de Teodoro Picado y los esfuerzos del gobierno por resolver el conflicto. Anunciaron que desde el 14 de marzo, el gobierno costarricense suspendió las garantías constitucionales. Pese a que Colombia está viviendo la crisis de violencia que se conoce como "el Bogotazo", no deja de sorprender la importancia que se le da al enfrentamiento civil en Costa Rica.

Es impactante observar esos acontecimientos de violencia en una ciudad como Bogotá que es la sede de la IX Conferencia de las Américas, actividad que no se detuvo, dada su importancia y que se traslada a Medellín. Desde este foro, la prensa publica diversas notas diplomáticas que se envían a los correspondientes gobiernos sobre el conflicto que se vive tanto en Colombia como en Costa Rica. Nicaragua, Guatemala y México, desde esta conferencia, defienden sus posiciones gubernamentales acerca de su neutralidad, su participación o no en la venta y llegada de armamento a Costa Rica.

El tiempo de Colombia, en noviembre de 1976 publicó una entrevista a Fidel Castro, quien refiriéndose a los sucesos vividos en Colombia decía: "Gaitán no solamente tenía un enorme arraigo entre las masas; tenía también grandes simpatías en el propio ejército de Colombia... no es de extrañar que la oligarquía colombiana en medio de una ola de sangre, fraguara el asesinato de aquel formidable adversario al que realmente temían. El día 9 de abril salimos nosotros del hotel en espera de la entrevista que tendríamos con Gaitán, eran como las
11 de la mañana aproximadamente, cuando gentes como enloquecidas comenzaron a correr por las calles repletas de público, gritando con ojos de indescriptible asombro: ¡Mataron a Gaitán! Y así la noticia se esparció como un reguero de pólvora por toda la ciudad (El Tiempo, 14 de noviembre de 1976).

Lo que sucede en Colombia es de suma importancia para toda América, con gobiernos democráticos y no democráticos. Los intereses de Estados Unidos están muy dirigidos a controlar esa instancia que será, finalmente, la Organización de Estados Americanos.

Siguiendo con este tema y entrelazándolo con Guatemala, el 20 de marzo de 1948 en El Imparcial, bajo el título "Revuelta tica un obstáculo a la conferencia de Bogotá", dice que los Estados Unidos se disponían a ampliar todos los medios diplomáticos para llegar a una solución de los disturbios políticos que han estallado en Costa Rica; también se manifiesta la importancia militar para los Estados Unidos por la cercanía con el Canal de Panamá y porque en los "sucesos" participan elementos comunistas adeptos al actual gobierno de Costa Rica. Continúa: "Se tiene entendido que los Estados Unidos expusieron sus puntos de vista a los gobiernos interesados en los sucesos de Costa Rica, la propia Costa Rica, Nicaragua y Guatemala...funcionarios norteamericanos han dicho enfáticamente que los problemas internos de los países ponen en riesgo las políticas del hemisferio por las necesidades....recordaron que este es un momento grave en la historia mundial...Los choques internos de Costa Ricas están acusando una conturbadora 
tendencia a envolver a otras naciones centroamericanas y del Caribe... La certeza de amenaza de guerra es razón suficiente para estudiar una acción si fuera necesaria...." (El resaltado es nuestro).

\section{Reflexiones finales}

Repensando lo expuesto sobre la dimensión periodística en esta selección de prensa internacional sobre la guerra civil de Costa Rica, se manifiesta esta concatenación de sucesos en la complejidad política de una guerra civil donde sus vecinos son parte y testigos de dos caras. El pensamiento nos devuelve a ponderar las partes y sus gobiernos, o los gobiernos y sus líderes opositores. México y su diplomática comprensión de sus huéspedes y refugiados políticos el trasiego de armas desde Estados Unidos por tierra, mar y aire, la participación abierta del gobierno de Guatemala, de su ejército, aviación y pertrechos; la participación de antisomocistas y del gobierno de Nicaragua, de antitrujillistas; la participación del gobierno de Estados Unidos, su ejército y la de sus diplomáticos. Una guerra civil donde convergen los diversos intereses geopolíticos de Estados Unidos, pendiente de la violencia política de Colombia, donde sus bases militares peligran, y de su objetivo principal, su Canal de Panamá y las presiones sociales de patriotas panameños, la ambición de marcar su poderío y su control político en contra de los movimientos sociales de la izquierda.

Todos los elementos se accionaban y, efectivamente, la zona se "limpia y se arrasa" de las organizaciones de trabajadores, de los lideres sindicales que simpatizaban con el Partido Comunista, del Partido Comunista y de sus líderes. Se reforma la Constitución para excluirlos. La memoria política que guarda la prensa nos amplía el conocimiento con múltiples nuevas conexiones que podemos entablar a manera de diálogo con esta. Estas relaciones internacionales, sus visiones y perspectivas constituyen la verdadera visión mesoamericana del entorno y la esencia de la guerra. Un caos y un orden porque son estos mismos países los testigos de las reuniones en la Embajada de México para las negociaciones por la paz: México, Chile, República Dominicana y Cuba. En los días de la Conferencia Interamericana en Bogotá, espacio donde la guerra y sus acontecimientos llegan.

El entramado de conexiones militares, tanto formales como informales en el área centroamericana y del Caribe en diferentes hechos militares, ha mostrado las conexiones de estas élites en diversos complots y en organizaciones de exiliados desde Costa Rica, México, Guatemala, El Salvador, Nicaragua y Panamá. A José Figueres se le expulsa de Costa Rica en 1942 por actividades contra el gobierno de Rafael Ángel Calderón Guardia. Se conecta en México con el exiliado antisomocista Rosendo Argüello y organizan, junto con otros exiliados hondureños y nicaragüenses, la denominada Legión del Caribe que además de constituirse en un frente político se organiza para comprar armas hacer acopio de ellas y enviarlas por diversas rutas, por tierra y por mar a Costa Rica, donde Figueres organiza su golpe de Estado.

Rosendo Argüello y Figueres, a finales de 1945, inician los planes para la compra de 
armas. "Chester Lacayo fue el encargado de hacer, por lo que hizo tratos con el General Gallo, militar mexicano quien se las vendió de mala calidad". Esto trajo un conflicto entre el general Lacayo y los nicaragüenses pues lo acusaron de estafador, lo que le costó su salida de los planes revolucionarios, así lo confirmaron los agentes de la Dirección General de Investigaciones Políticas y Sociales (IPS). "Esta dirección de inteligencia fue fundada en 1915 para actividades de espionaje" (Barahona, 2015, citando a Laura Moreno).

Los planes continuaron en México y Rosendo Argüello relata que "en ese enorme avión pensábamos llevar las armas hasta un aeropuerto secreto situado en otro Estado (de México), de donde un avión que teníamos arreglado las llevaría a su destino en Costa Rica. Desde 1945 teníamos planeado entrar en Costa Rica por San Isidro y Dominical, y por eso le llamábamos Plan Sunday. Por esos lugares de todos modos entraron las armas en 1948 para dar comienzo a la "Revolución de Figueres" (Barahona, 2015).

La posibilidad de que el armamento llevado a Costa Rica provenía de México y Nicaragua y que hubiera sido llevado al país vecino, desde algún tiempo atrás se discutía en la prensa nacional, aunque se supo rápidamente de la ayuda de Guatemala en marzo 1948: "El trasiego de armas es una realidad constatada en los archivos de la Dirección de Investigaciones Políticas de México a la que han tenido acceso diferentes investigadores mexicanos. EL trabajo de la doctora Laura Moreno, analiza el entramado de los vínculos de dirigentes centroamericanos y caribeños desde
México [.. ¿ ¿Por qué Costa Rica fue el primer país que apoyó el movimiento para el derrocamiento de Picado y no Nicaragua como se planeó originalmente? [...] Arévalo, presidente de Guatemala y Figueres, líder costarricense entablaron una amistad muy cercana, la cual aprovechó Figueres para proponer a Arévalo su planes, proponiéndole la conformación de la federación de países de Centroamérica y el Caribe, de la cual sería el primer presidente. Arévalo aceptó y el 16 de diciembre de 1947 se firmó en Guatemala el Pacto, este Pacto fue firmado por Emiliano Chamorro, representante de Nicaragua, Juan Rodríguez García, representante de República Dominica y José Figueres de Costa Rica, entre otros". (Barahona, 2015).

El diario Panamá América dice: "Gobierno suspendió las garantías constitucionales, a la vez que ordenó reforzar la guardia de la frontera con Panamá pues se ha informado que se pretende pasar armas por Bocas del Toro hacia Costa Rica. Se dice que un avión dejó caer cerca de donde se encuentran los rebeldes en Villa Mills un saco con revólveres que fueron capturados por el Gobierno" (1948).

El contrapunto entre la información ya publicada por los historiadores de la Guerra Civil de 1948 con los datos que presentan estos medios escritos, ofrece un sinnúmero de posibilidades para nuevos estudios y nuevas perspectivas de un suceso tan crucial en la vida costarricense.

Consideramos que nuevas interpretaciones deben construirse con base en este importante acopio documental: análisis de memorias militares, sobre la violencia contra 
los partidos políticos, sindicatos, líderes sociales y mujeres, la violencia como objeto de estudio y sus formas de dominación para superar las visiones aisladas y transformar nuestra visión de país por uno más complejo y diverso. Según Mendoza, García (2018): "Ante todo esto que aquí se expone la pregunta que surge es ilos relatos distintos que se contraponen a la historia oficial posibilitan la formación de memorias colectivas? La respuesta es sí, un tipo de memoria. En tanto que un relato distinto, contenidos distintos, forjan memorias distintas. Y en tanto que una narración de un evento pasado no intenta imponerse por sobre otras narraciones, sólo demanda su reconocimiento, entonces no estamos ante un ejercicio de historia ni de contrahistoria, sino de memoria colectiva. De lo que se trata, en todo caso, no es de suplir una versión por otra, sino del reconocimiento de lo que se ha negado $\mathrm{u}$ ocultado. De ampliar, en sentido estricto, el relato sobre el pasado y sus sucesos y sus personajes. $\mathrm{Y}$ de esa manera tener distintas perspectivas". Así también esperamos humanizar la academia, proveyendo el acercamiento de este tema al público y a los estudiantes, así como al investigador, ampliando nuestro pasado, a las víctimas y volver a leer lo vedado.

\section{Referencias}

Aguilar, O. (1970). Costa Rica y sus hechos políticos de 1948.San José, Costa Rica: Editorial Costa Rica.

Barahona, M. (2009). Centenario de Manuel Mora y los últimos días de la guerra civil. Revista Estudios, $\mathrm{N}^{\circ}$. 22, Universidad de Costa Rica.
Barahona, M. (2015) Nuevos documentos de 1948. Los proscriptos. San José, Costa Rica: Editorial Costa Rica.

Díaz, D. (2015). Crisis social y memorias en lucha: guerra civil en Costa Rica, 1940-1948.San José, Costa Rica: Editorial de la Universidad de Costa Rica.

Mendoza, García (2018). El pasado en disputa : memoria e historia como marcos en la enseñanza. Boletín Electrónico de Investigación de la Asociación Oaxaqueña de Psicología. México.

Moreno, L. (2008). Espionaje mexicano. México: Escuela Nacional de Antropología e Historia.

Moreno, L. (2018). “A 70 años de la Guerra Civil 1948, José Figueres en México“. En: Revista Estudios N ${ }^{\circ} .37$. https://revistas.ucr.ac.cr/index.php/ estudios/issue/view/2719 (Consultado el 11 de abril de 2019).

Villamízar, H. y Aguilar, S. (2017). "Conferencia Panamericana de 1948". https://cpri.javeriana.edu.co/documents/2141973/10031911/ conferencia-panamericana-1948. pdf/b687d7c1-26b7-4134-80d043b89a4ee49e (Consultado el 10 de abril de 2019).

\section{Producción audiovisual}

Jara, E. y Jara, A. (producción y dirección) (2014). El codo del diablo. San José, Costa Rica.

Producción Canal Universitario. Universidad de Costa Rica. Alarcón, A. (guion y realización) y Barahona, M. (producción, investigación y guion) (2000). 


\section{Periódicos}

México: del 12 de marzo de 1948 al 24 de abril de 1948

El Excelsior

El Nacional

El Universal

Panamá: del 12 de marzo de 1948 al 24 de abril de 1948

La Hora

Panamá América

La Nación
Guatemala: del 12 de marzo de 1948 al 24 de abril de 1948

El Imparcial

Chile: del 12 de marzo de 1948 al 24 de abril de 1948

El Mercurio

Colombia: del 12 de marzo de 1948 al 24 de abril de 1948

El tiempo 